\title{
Estimating the effects of population size and type on the accuracy of genetic maps
}

\author{
Adésio Ferreira ${ }^{1}$, Marcia Flores da Silva ${ }^{2}$, Luciano da Costa e Silva ${ }^{1}$ and Cosme Damião Cruz ${ }^{1}$ \\ ${ }^{1}$ Universidade Federal de Viçosa, Departamento de Biologia Geral, Viçosa, MG, Brasil. \\ ${ }^{2}$ Universidade Federal de Viçosa, Departamento de Bioquímica e Biologia Molecular, Viçosa, MG, Brazil.
}

\begin{abstract}
Based on simulation studies, it was shown that the type and size of experimental populations can exert an influence on the accuracy of genetic maps. A hypothetical genome map (one chromosome with nine equidistant molecular markers) was generated for the following population types: $F_{2}$ with dominant and co-dominant markers, backcrossing, recombinant inbred lines (RIL) and double-haploid. The population sizes were 50, 100, 150, 200, 500 and 1000 individuals and 100 simulations were made for each population. The inaccuracies of the populations with the lowest number of individuals were shown by inversions in the order of the markers and the establishment of more than one linkage group in up to $38 \%$ of the simulations, depending on the population type. Stress and variance values of the distances between adjacent markers were significantly reduced with the increased size of the population. More accurate maps were obtained for the co-dominant $F_{2}$ and $\mathrm{RIL}$ whereas the maps for the dominant $\mathrm{F}_{2}$ population were less accurate. The higher the number of individuals, the more precise was the map. In all populations, a total of 200 individuals were considered as being sufficient for the construction of reasonably accurate genetic maps. Although this paper deals with plant populations this approach is equally applicable to other organisms.
\end{abstract}

Key words: experimental populations, mapping, simulation, markers.

Received: August 20, 2004; Accepted: May 31, 2005.

Genetic maps provide important information for detailed genetic analysis of qualitative and quantitative traits and have proven to be important tools for plant improvement (Mohan et al., 1997; Doerge, 2002) because they allow workers to evaluate the similarity between genes regulating the expression of a phenotype in different populations and species (Paterson et al., 2000; Ahn and Tanksley, 1993). Another important factor is that such maps constitute the first step towards positional cloning of the genes responsible for a specific phenotype, with ultra-dense genetic maps being necessary for these types of studies (Mohan et al., 1997). Simulation studies are also very important in the development of statistical methodologies for both the construction of genetic maps and mapping studies of quantitative trait loci (QTL) (Darvasi et al., 1993).

The currently available literature in this area shows that genetic maps are constructed using different types and sizes of mapping populations, laboratory techniques, marker systems, mapping strategies, statistical procedures

Send correspondence to Adésio Ferreira. Universidade Federal de Viçosa, Departamento de Biologia Geral, Rua Senador Vaz de Melo 95 F, 36570-000 Viçosa, MG, Brazil. E-mail: adesio@vicosa. ufv.br. and computer packages. These factors can affect the efficiency of the mapping process because of differences in the genetic distances between markers that can occur by variations in the degree of recombination observed in different crossings (Liu, 1998), and this is true even if different maps are generated for the same specie (Paterson et al., 2000).

Distinct types of experimental populations have been employed for mapping of crop species in order to study QTL, including: $\mathrm{F}_{2}$ populations; backcrossings (BC); recombinant inbred lines (RIL); and double haploids (DH) (Doerge, 2002; Burr et al., 1988; He et al., 2001). As long as the $\mathrm{F}_{2}$ and $\mathrm{BC}$ populations are considered to be temporary populations, they cannot be indefinitely. The $\mathrm{DH}$ and RIL populations are considered to be permanent and can be maintained under several experimental conditions (He et al., 2001).

During the determination of recombination frequencies, used in the establishment of the linkage groups under a determined statistical confidence, the size of the population is a function of the experimental population type, the nature of the markers involved and the required statistical confidence. In addition, the genetic density of the markers in the map is limited not only by the number of markers but also by the number of recombination events occurring in meio- 
sis that are represented in the mapped population (Liu, 1998).

When the main focus is the detection of QTL, the size of the mapped population may be determined by the gene effect to be detected as well as the type of population (Soller et al., 1976; Lander and Botstein, 1989; Lynch and Walsh, 1998). In this case, the resolution of the mapped QTL depends more on the size of the mapped population and less on to the effect of the QTL (Darvasi et al., 1993). Melchinger et al. (1998) claim that the majority of experiments with replicates have used a total of 100 to 200 individuals or progenies and this choice of population size happens due to the excessive work and costs associated with phenotyping and genotyping in large populations.

In spite of the availability of several papers on genetic mapping, specific studies relating to the determination of the ideal number of individuals in a given population needed to establish accurate genetic maps have as yet been inconclusive. The clarification of this aspect is extremely important for optimizing the time and costs associated with molecular analyses allowing breeding programs to obtain improved lines in selective process with the maximum efficiency. This paper describes simulation studies aimed at establishing the accuracy of genetic mapping in different experimental populations used in breeding programs, as well as verifying how the size of these populations affects the quality of genetic maps.

A hypothetical genome composed of a single 81.093 centimorgan (cM) linkage group and nine equally spaced molecular markers was developed and used to simulate $\mathrm{BC}$ populations: $F_{2}$ with dominant markers; $F_{2}$ with co-dominant markers; recombinant inbred lines (RIL); and double haploids (DH). Each population type was investigated for population sizes of 50,100,150, 200, 500 and 1000 individuals. When a total of 100 replicates were performed in each case, 3,000 simulated populations were generated.

The simulation process was performed using the following steps: 1) simulation of a single $81.093 \mathrm{cM}$ linkage group and nine equidistant molecular markers, from which the recombination percentages were expressed using Kosambi's mapping function; 2) establishment of the homozygous and contrasting diploid genitors for the nine markers generating $F_{1}$ individuals, with all markers in the coupling phase; 3 ) simulation of a gametic group proceeding from $F_{1}$ to form mapping populations. A biological model was adopted in which the pairing of homologous chromosomes and the exchanges between these chromosomes took place among regions delimited by the markers. The probability for recombination in a region between adjacent markers is given by the genomic distance between the markers, e.g. if the genomic distance (r) between the first two markers in the chromosome is $10 \mathrm{cM}$ the recombination probability in this region will be $10 \%$. Concerning the simulation of the RIL population obtained after successive cycles of self-pollination, the recombination probabil- ity in this region will be $16.667 \%$ (i.e. $\left[\mathrm{r}^{\prime}=2 \mathrm{r} /(1+2 \mathrm{r})\right]$ ) and it was also assumed that the interference was null; 4) the generation of a single individual in the population involved 10,000 gametes of each genitor and from this pool two gametes were used for the $\mathrm{BC}$ or $\mathrm{F}_{2}$ populations and only one was used for the DH and RIL populations.

Using the dataset simulated for each population type and size, genetic maps were constructed considering the maximum recombination frequency to be $30 \mathrm{cM}$ and a logarithm of odds (LOD score) minimum of 3 as the major criteria in evaluating the linkage between two markers. The simulations and analyses were accomplished by using the GQMOL (2004) program.

The accuracy of the maps obtained in relation to the original linkage group (with $81.093 \mathrm{cM}$ and nine equally spaced markers,) considered to be the true one, was established after taking into account the following criteria:

\section{Size of the linkage group}

This is given by the sum of the distances between adjacent markers in the linkage group.

$$
\mathrm{L}=\sum_{\mathrm{k}=1}^{\mathrm{m}-1} \mathrm{~d}_{\mathrm{k}},
$$

where $L$ is the size of the linkage group and $d_{k}$ is the distance between the adjacent markers $m_{k}$ and $m_{k+1}$ in the analyzed linkage group $(\mathrm{k}=1, \ldots, \mathrm{m}-1)$. Being $\mathrm{m}$ the number of markers in the analyzed linkage group.

\section{Average distance of two adjacent markers in the linkage group}

This is the ratio of the linkage group size by the interval numbers between adjacent markers in the linkage group.

$$
\overline{\mathrm{d}}=\frac{\mathrm{L}}{\mathrm{m}-1}
$$

\section{Variances of the distances between adjacent markers}

This measure proved to be useful since the original linkage group presented equidistant markers. Consequently, the variance was null.

$$
\sigma^{2}=\frac{\sum_{k=1}^{m-1}\left(d_{k}-\bar{d}\right)^{2}}{I-1},
$$

being I the interval numbers given by $\mathrm{m}-1$.

\section{Stress}

The stress coefficient (S) was used to evaluate the adjustment between distances in the original genome and those in linkage group obtained from simulated population. Stress was established for reasons similar to those presented by Cruz and Carneiro (2003) in genetic divergence studies. 


$$
\mathrm{S}=100 \cdot \sqrt{\sum_{\mathrm{k}=1}^{\mathrm{m}-1}\left(\mathrm{~d}_{\mathrm{ok}}-\mathrm{d}_{\mathrm{k}}\right)^{2} / \sum_{\mathrm{k}=1}^{\mathrm{m}-1} \mathrm{~d}_{\mathrm{ok}}^{2}}
$$

where $d_{o k}$ is the distance between the adjacent markers $m_{k}$ and $m_{k+1}$ in the original genome (true) and $d_{k}$ is the distance between the adjacent markers $m_{k}$ and $m_{k+1}$ in the analyzed linkage group $(\mathrm{k}=1, \ldots, \mathrm{m}-1)$.

\section{Spearman correlation}

This was used to evaluate the degree of concordance between the ordering of the markers in each analyzed linkage group and the original one.

$$
\mathrm{r}_{\mathrm{s}}=1-\frac{6 \sum_{\mathrm{k}=1}^{\mathrm{m}} \Delta_{\mathrm{k}}^{2}}{\mathrm{~m}\left(\mathrm{~m}^{2}-1\right)},
$$

where $\Delta_{\mathrm{k}}$ is the difference between the code attributed to the marker $\mathrm{m}_{\mathrm{k}}(\mathrm{k}=1, \ldots, \mathrm{m})$ at position $\mathrm{k}$ of the original genome and the code of the $m_{k}$ marker located at the respective k position of the linkage group obtained from the simulated population.

The minimum number of individuals in the population leading genome length, distances and mark sequences similar to the original linkage group was considered as the ideal population size. Since 100 replicates were generated from each simulation study, the analyses were based on the average values of the previously described criteria.

The type and size of the populations proved to affect the accuracy of the genetic mapping. Concerning size, the populations with 50 and 100 individuals were the ones unable to reconstitute the original (or true) genome and they also presented the less accurate genetic maps (Table 1). In populations containing 50 individuals (except for the codominant $\mathrm{F}_{2}$ population), the establishment of more than one linkage group was observed in approximately $38 \%$, $23 \%, 2 \%, 1 \%$ of the simulations for the RIL, dominant $\mathrm{F}_{2}$, $\mathrm{BC}$ and $\mathrm{DH}$ populations respectively. These results indicate that this proposed population size is not adequate considering that the expectation would be to reconstitute only a single linkage group. In addition, inversions in the order of the markers were observed (as indicated by the Spearman correlation (r) differing from 1 in all the population types (Table 1 ). In populations containing 100 individuals only $2 \%$ of the simulations using the RIL population presented the establishment of more than one linkage group, and there was an inversion in the order of the markers for the dominant $\mathrm{F}_{2}$, BC and RIL populations. Moreover, it was evident that populations with a lower number of individuals showed higher stress values and higher distance variances as well as wider deviation in these estimates and in the estimates of the genome size (Table 2). All these results pointed to the low levels of accuracy of the information obtained with genetic maps generated from studies with a relatively low number of individuals.

In all population types the increase in the number of individuals provided less variable measures of genome size as well as variance in both intervals and stress in the 100 simulations performed for each case (Table 2). In addition, stress values and the variance interval showed a statistically significant reduction when the population size was increased (Table 2). Therefore, the mapping accuracy increases with an increased number of individuals in the population.

\begin{tabular}{|c|c|c|c|c|c|}
\hline \multirow[b]{2}{*}{ Population } & \multicolumn{5}{|c|}{ Number linkage groups } \\
\hline & $\begin{array}{l}1 \text { linkage group } \\
\text { with } 9 \text { markers }\end{array}$ & $\begin{array}{l}1 \text { linkage group } \\
\text { with } 8 \text { markers }\end{array}$ & $\begin{array}{l}2 \text { linkage } \\
\text { groups }\end{array}$ & $\begin{array}{l}3 \text { linkage } \\
\text { groups }\end{array}$ & $\begin{array}{l}\text { With Spearman } \mathrm{r} \\
\text { different from } 1^{\mathrm{b}}\end{array}$ \\
\hline \multicolumn{6}{|l|}{$\mathrm{F}_{2}$ dominant } \\
\hline 50 & 62 & 7 & 23 & - & 8 \\
\hline 100 & 96 & - & - & - & 4 \\
\hline \multicolumn{6}{|c|}{ Backcrossing } \\
\hline 50 & 87 & - & 2 & - & 11 \\
\hline 100 & 99 & - & - & - & 1 \\
\hline \multicolumn{6}{|l|}{ RIL } \\
\hline 50 & 66 & 1 & 23 & 5 & 5 \\
\hline 100 & 99 & - & - & - & 1 \\
\hline \multicolumn{6}{|c|}{ Duble haploid } \\
\hline 50 & 88 & - & 1 & - & 11 \\
\hline \multicolumn{6}{|c|}{$\mathrm{F}_{2}$ co-dominant } \\
\hline 50 & 96 & - & - & - & 4 \\
\hline
\end{tabular}

Table 1 - Number linkage groups formed and Spearman correlation differing from 1 for different population types and sizes.

${ }^{a}$ Excluding the groups with nine markers that presented a Spearman correlation coefficient (r) different from 1. ${ }^{\mathrm{O}}$ Only for the cases of one linkage group with nine markers. 
Table 2 - Average linkage group size, distance between adjacent linkage group markers and stress in different population types and sizes.

\begin{tabular}{|c|c|c|c|c|c|c|c|}
\hline Population & $\begin{array}{l}\text { Linkage group } \\
\text { size }(\mathrm{cM})\end{array}$ & $\begin{array}{l}\text { Linkage group } \\
\text { size standard } \\
\text { deviation }(\mathrm{cM})\end{array}$ & $\begin{array}{c}\text { Average distance } \\
\text { between adjacent } \\
\text { markers }(\mathrm{cM})\end{array}$ & $\begin{array}{l}\text { Average distance } \\
\text { variance }(\mathrm{cM})\end{array}$ & Stress & $\begin{array}{c}\text { Stress standard } \\
\text { deviation }\end{array}$ & $\begin{array}{l}\text { Evaluated repli- } \\
\text { cate numbers }\end{array}$ \\
\hline \multicolumn{8}{|l|}{ RIL } \\
\hline 50 & $81.43 \mathrm{~b}$ & 8.82 & $10.39 \mathrm{a}$ & $11.84 \mathrm{a}$ & $32.44 \mathrm{a}$ & 7.60 & 54 \\
\hline 100 & $84.12 \mathrm{a}$ & 8.19 & $10.51 \mathrm{a}$ & $7.99 \mathrm{~b}$ & $27.30 \mathrm{~b}$ & 7.18 & 97 \\
\hline 150 & $83.78 \mathrm{ab}$ & 6.86 & $10.47 \mathrm{a}$ & $6.15 \mathrm{c}$ & $23.50 \mathrm{c}$ & 7.30 & 100 \\
\hline 200 & $84.48 \mathrm{~b}$ & 5.61 & $10.56 \mathrm{a}$ & $4.46 \mathrm{~d}$ & $20.44 \mathrm{~d}$ & 5.21 & 100 \\
\hline 500 & $82.96 \mathrm{ab}$ & 3.83 & $10.37 \mathrm{a}$ & $1.69 \mathrm{e}$ & $12.57 \mathrm{e}$ & 3.73 & 100 \\
\hline 1000 & $83.45 \mathrm{ab}$ & 2.34 & $10.43 \mathrm{a}$ & $0.77 \mathrm{e}$ & $8.71 \mathrm{f}$ & 2.55 & 100 \\
\hline \multicolumn{8}{|l|}{$\mathrm{F}_{2}$ dominant } \\
\hline 50 & $75.12 \mathrm{~b}$ & 10.69 & $9.39 \mathrm{~b}$ & $16.83 \mathrm{a}$ & $39.61 \mathrm{a}$ & 9.54 & 62 \\
\hline 100 & $82.12 \mathrm{a}$ & 9.51 & $10.26 \mathrm{a}$ & $12.40 \mathrm{~b}$ & $33.15 \mathrm{~b}$ & 9.78 & 100 \\
\hline 150 & $80.41 \mathrm{a}$ & 7.51 & $10.05 \mathrm{a}$ & $7.01 \mathrm{c}$ & $25.21 \mathrm{c}$ & 6.88 & 100 \\
\hline 200 & $81.07 \mathrm{a}$ & 7.21 & $10.13 \mathrm{a}$ & $5.92 \mathrm{c}$ & $23.36 \mathrm{c}$ & 6.10 & 100 \\
\hline 500 & $80.69 \mathrm{a}$ & 4.50 & $10.08 \mathrm{a}$ & $2.36 \mathrm{~d}$ & $14.81 \mathrm{~d}$ & 3.62 & 100 \\
\hline 1000 & $80.47 \mathrm{a}$ & 2.80 & $10.06 \mathrm{a}$ & $1.22 \mathrm{~d}$ & $10.44 \mathrm{e}$ & 2.65 & 100 \\
\hline \multicolumn{8}{|c|}{$\mathrm{F}_{2}$ co-dominant } \\
\hline 50 & $82.48 \mathrm{a}$ & 9.44 & $10.30 \mathrm{a}$ & $11.13 \mathrm{a}$ & $31.98 \mathrm{a}$ & 7.93 & 96 \\
\hline 100 & $79.03 \mathrm{~b}$ & 7.32 & $9.88 \mathrm{~b}$ & $5.35 \mathrm{~b}$ & $22.46 \mathrm{~b}$ & 6.24 & 100 \\
\hline 150 & $80.52 \mathrm{ab}$ & 6.01 & $10.06 \mathrm{ab}$ & $4.00 \mathrm{c}$ & $19.16 \mathrm{c}$ & 5.37 & 100 \\
\hline 200 & $80.03 \mathrm{~b}$ & 4.86 & $10.00 \mathrm{ab}$ & $3.05 \mathrm{c}$ & $16.66 \mathrm{~d}$ & 4.49 & 100 \\
\hline 500 & $80.48 \mathrm{ab}$ & 3.31 & $10.06 \mathrm{ab}$ & $1.31 \mathrm{~d}$ & $11.03 \mathrm{e}$ & 2.77 & 100 \\
\hline 1000 & $80.03 \mathrm{ab}$ & 2.20 & $10.00 \mathrm{ab}$ & $0.68 \mathrm{~d}$ & $7.92 \mathrm{f}$ & 2.00 & 100 \\
\hline \multicolumn{8}{|c|}{ Backcrossing } \\
\hline 50 & $81.21 \mathrm{a}$ & 11.11 & $10.15 \mathrm{a}$ & $21.87 \mathrm{a}$ & $43.73 \mathrm{a}$ & 11.75 & 87 \\
\hline 100 & $81.05 \mathrm{a}$ & 8.03 & $10.13 \mathrm{a}$ & $9.92 \mathrm{~b}$ & $29.57 \mathrm{~b}$ & 8.25 & 99 \\
\hline 150 & $81.63 \mathrm{a}$ & 6.78 & $10.20 \mathrm{a}$ & $6.86 \mathrm{c}$ & $24.67 \mathrm{c}$ & 6.80 & 100 \\
\hline 200 & $81.42 \mathrm{a}$ & 6.08 & $10.18 \mathrm{a}$ & $5.34 \mathrm{c}$ & $21.74 \mathrm{~d}$ & 6.17 & 100 \\
\hline 500 & $81.88 \mathrm{a}$ & 3.67 & $10.23 \mathrm{a}$ & $1.98 \mathrm{~d}$ & $13.46 \mathrm{e}$ & 3.07 & 100 \\
\hline 1000 & $80.60 \mathrm{a}$ & 2.52 & $10.07 \mathrm{a}$ & $1.07 \mathrm{~d}$ & $9.70 \mathrm{f}$ & 2.73 & 100 \\
\hline \multicolumn{8}{|c|}{ Double-haploid } \\
\hline 50 & $81.09 \mathrm{a}$ & 13.44 & $10.15 \mathrm{a}$ & 19.89 a & $42.74 \mathrm{a}$ & 11.75 & 88 \\
\hline 100 & $81.00 \mathrm{a}$ & 9.77 & $10.12 \mathrm{a}$ & $9.99 \mathrm{~b}$ & $30.44 \mathrm{~b}$ & 8.28 & 100 \\
\hline 150 & $79.83 \mathrm{a}$ & 7.20 & $9.98 \mathrm{a}$ & $6.65 \mathrm{c}$ & $24.65 \mathrm{c}$ & 6.28 & 100 \\
\hline 200 & $80.26 \mathrm{a}$ & 7.33 & $10.03 \mathrm{a}$ & $4.79 \mathrm{c}$ & $21.53 \mathrm{~d}$ & 5.15 & 100 \\
\hline 500 & $80.74 \mathrm{a}$ & 3.71 & $10.09 \mathrm{a}$ & $1.89 \mathrm{~d}$ & $13.20 \mathrm{e}$ & 3.17 & 100 \\
\hline 1000 & $80.59 \mathrm{a}$ & 2.93 & $10.07 \mathrm{a}$ & $1.11 \mathrm{~d}$ & $10.10 \mathrm{f}$ & 2.42 & 100 \\
\hline
\end{tabular}

Notes: For each population the same letter in the same column indicates that there was no statistically significant difference between the averages by the

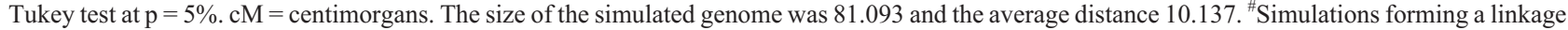
group with the nine markers and without inversion in the marker order.

The higher the number of individuals the better the estimate of the genome size, as indicated by the lowest stress. This raises the question as to what is the maximum acceptable stress value that can be used for mapping. The average stress values in the populations depended on population size (n) and were: $32 \%$ to $43.7 \%$ for $n=50 ; 22 \%$ to
$33 \%$ for $\mathrm{n}=100 ; 19 \%$ to $25 \%$ for $\mathrm{n}=150 ; 16.5 \%$ to $23 \%$ for $\mathrm{n}=200 ; 11 \%$ to $14 \%$ for $\mathrm{n}=500$; and $7.9 \%$ to $10.4 \%$ for $\mathrm{n}=1000$. In all cases, the co-dominant $\mathrm{F}_{2}$ population showed the lowest variation whereas the dominant $F_{2}$ population presented the highest variation. For a better understanding of the meaning of stress, it may be explained as a 
function of the average deviation of the distances both between adjacent markers in the linkage group and those in the original genome. Therefore, the previously expression of stress can be rewritten as $\mathrm{S}=\left[\left(\mathrm{d} / \mathrm{d}_{0}\right) .100\right]$, where $d$ is the average deviation of the distances by interval in the analyzed linkage group in relation to the original genome, and $\mathrm{d}_{\mathrm{o}}$ is the distance between adjacent markers in the original genome (10 cM in this case). For instance, a stress value of $20 \%$ corresponds to an average deviation of $2 \mathrm{cM}$ for each interval in the linkage group, that is, if the real distance between two adjacent markers is $10 \mathrm{cM}$ and if a $20 \%$ stress is acceptable, the distance might vary from 8 to $12 \mathrm{cM}$. Then, the researcher should decide if this variation might or might not interfere with the objectives of the mapping study.

In order to verify the differences between the population types, a comparison between the averages obtained for those populations containing 1,000 individuals was made. It was assumed that these populations are more stable, so the differences between them are more likely to be related to the type and not to the size of the population. The co-dominant $\mathrm{F}_{2}$ and RIL populations presented the lowest average stress (7.92 $\mathrm{F}_{2}$ and $8.71 \%$ for the RIL population), whereas the dominant $\mathrm{F}_{2}$ population showed the highest stress value (10.44\%). The differences between the averages proved to statistically significant (Tukey test at $\mathrm{p}=5 \%$ ). Both the RIL and co-dominant $\mathrm{F}_{2}$ populations presented lower distance variances between adjacent markers in the linkage group than did the other population types, indicating that these populations would provide the highest levels of accuracy in genetic mapping.

The performance of each population type relative to the increase in the number of individuals in the population is shown in Table 2. Taking into account the average size of the genome and the average distance in the $\mathrm{DH}$ and $\mathrm{BC}$ populations, there were no statistically significant differences in the averages among the populations. However, for dominant $\mathrm{F}_{2}$ and RIL populations, both the average of the genome size and the average distance were lower in the map constructed with 50 individuals than were those containing other population sizes. Stress and variance values were significantly reduced with the increased number of individuals for all populations. Thus, to obtain a more reliable genetic map it is necessary to use experimental populations with higher numbers of individuals.

The $\mathrm{F}_{2}$ population provided the best and the worst estimates for stress and variance, depending on the marker type to be used. The $\mathrm{F}_{2}$ population with co-dominant markers showed the lowest values for stress and variance for all population sizes, whereas RIL was the second best population. Taking into account the importance of this population in the design of QTL mapping experiments, this result is important because RIL populations allow replicates of the same genotype, a process which minimizes the environmental error.
According to Burr and Burr (1991), the choice of the population type for genetic mapping might have important consequences concerning the efficiency and utility of the genetic information. Hanson (1959) and Liu (1998) demonstrate that a given population size affects the power to detect linkage as well as the estimate and accuracy of the recombination frequency. In addition, the type of markers should also be taken into account when an experiment with genetic mapping is established.

In the present study, the genetic mapping conducted with populations containing of 50 and 100 individuals was clearly inadequate, as indicated by different comparison parameters and different population types. Considering that the original genome had a satisfactory degree of saturation (around $10 \mathrm{cM}$ between each marker) the low number of recombination events in the populations with a lower number of individuals might be the explanation for the establishment of more than one linkage group in the dominant $F_{2}$ population.

The inversion of marker order occurring in all types of population with a size of 50 and (more frequently) 100 individuals is described in the literature as a problem generated by both the size of the population and the saturation of the map. Liu (1998) used simulations to demonstrate that for a population of 100 individuals the confidence in the ordering is $90 \%$ and drops to $60 \%$ when the population size is 50. Liu also states that if the genes are strongly linked (i.e. 1 $\mathrm{cM}$ ) a large number of individuals are necessary to obtain the accurate gene order with high confidence.

For some genome mapping applications the accurate ordering of the markers and the high resolution of the linkage map are not always necessary. However, high levels of accuracy are necessary for QTL location aimed at positional gene cloning (Van Ooijen, 1992; Liu, 1998). In this case highly accurate estimates (between 1 and $2 \mathrm{cM}$ ) of QTL location are needed for application of the physical mapping and QTL cloning procedures (Darvasi et al., 1993) and detailed mapping techniques are necessary in order to obtain better resolution. However, from a plant breeding perspective the high accuracy of the distance estimates might not be so restrictive since the processes based on marker-assisted selection might become viable only with information about the markers flanking a given QTL, and such QTLs can be satisfactorily detected when it presents significant phenotypic effects (Van Ooijen, 1992).

Concerning different population types, both the $\mathrm{F}_{2}$ populations with co-dominant markers and RILs presented the most accurate mapping results. Nevertheless, it is wellknown that the RIL population is distinguished from the $\mathrm{F}_{2}$, $\mathrm{BC}$ and $\mathrm{DH}$ populations because it undergoes successive meiosis cycles, increasing the recombination probability of strongly linked genes. Therefore, RIL becomes a more efficient population to estimate the recombination frequency, mainly when the distances between markers are relatively small $(\mathrm{r}<12.5 \mathrm{cM})$. On the other hand, gene linkages above 
$20 \mathrm{cM}$ are not frequently detected in RIL because of high recombination frequencies (Burr et al., 1988). This might have serious consequences because it may lead to linkage not being detected when it in fact exists.

In the attempts to reconstitute the original genome a high frequency of two to three linkage groups was observed in the RIL population containing a low number of individuals but when the number of individuals increased the stress and variance estimates indicated that RIL always produced better results than the than those $\mathrm{BC}$, double hybrid and dominant $\mathrm{F}_{2}$ populations, demonstrating the relative efficiency of the RIL population for genetic mapping.

The accuracy of genetic mapping is a function of the size and type of the population under study since the accuracy of the genetic distance estimates is directly related to these two parameters. In all population types, populations of 500 and 1,000 individuals were the ones providing the best genetic maps relative to the original genome as shown by the fact that these populations had the lowest estimates of stress and variance of the distances between marker pairs in the linkage group. However, populations with a high number of individuals might not be viable because they increase the costs and require more labor, space and time for genetic mapping. Our results showed that in different populations a total of 200 individuals are enough for the construction of reasonably accurate genetic maps with the most efficient populations being the $F_{2}$ population with co-dominant markers and the RIL population. Thus, the number of individuals in the population may be determined as a function of the required accuracy level and the technical and scientific return on the information obtained. Therefore, the researcher should decide the reliability of the map, given the fact that constructing genetic maps with a higher or lower accuracy will influence the aims and costs of the study. One option would be to employ more informative populations and markers that allow the use of a lower number of individuals and maintain the efficiency of genetic mapping. Although this paper deals with plant populations this approach is equally applicable to other organisms.

\section{References}

Ahn S and Tanksley SD (1993) Comparative linkage maps of the rice and maize genomes. Proc Natl Acad Sci 90:7980-7984.
Burr B and Burr FA (1991) Recombinat inbreds for molecular mapping in maize: Theoretical and practical considerations. Trends Gent 7:55-60.

Burr B, Burr FA, Thompson KH, Albertson MC and Stuber CW (1988) Gene mapping with recombinant inbreds in maize. Genetics 118:519-526.

Cruz CD and Carneiro PCS (2003) Modelos biométricos aplicados ao melhoramento genético. v. 2. Editora UFV, Viçosa, $623 \mathrm{pp}$.

Darvasi A, Weinreb A, Minke V, Weller JI and Soller M (1993) Detecting marker-QTL linkage and estimating QTL gene effect and map location using a saturated genetic map. Genetics 134:943-951.

Doerge R (2002) Mapping and analysis of quantitative trait loci in experimental populations. Nature Reviews 3:43-52.

GQMOL, http://www. ufv.br/dbg/gqmol/gqmol.htm.

Hanson WD (1959) Minimum family size for the planning of genetic experiments. Agronomy Journal 51:711-715.

He P, Li JZ, Zheng XW, Shen LS, Lu CF, Chen Y and Zhu LH (2001) Comparison of molecular linkage maps and agronomic trait loci between DH and RIL populations derived from the same rice cross. Crop Science 41:1240-1246.

Kosambi DD (1944) The estimation of map distances from recombination values. Ann Eugen 12:172-75.

Lander ES and Botstein D (1989) Mapping Mendelian factors underlying quantitative traits using RFLP linkage maps. Genetics 121:185-199.

Liu HB (1998) Statistical Genomics, Linkage, Mapping and QTL Analysis. CRC, Boca Raton, Florida, 611 pp.

Lynch M and Walsh B (1998) Genetic Analysis of Quantitative Traits. Sinauer Associets, Sunderland, Massachusetts, 980 pp.

Melchinger AE, Utz HF and Schön CC (1998) Quantitative trait locus (QTL) mapping using different testers and independent population samples in maize reveals low power of QTL detection and large bias in estimates of QTL effects. Genetics 149:383-403.

Mohan M, Nair S, Bhagwat A, Krishna TG and Yano M (1997) Genome mapping, molecular markers and marker-assisted selection in crop plants. Molecular Breeding 3:87-103.

Paterson AH, Bowers JE, Burow MD, Draye X, Elsik CG, Jiang C-X, Katsar CS, Lan TH, Lin YR, Ming R and Wright RJ (2000) Comparative genomics of plant chromosomes. The Plant Cell 12:1523-1539.

Soller MT, Broddy T and Genizi A (1976) On the power of experimental designs for detection of linkage between marker loci and quantitative loci in crosses between inbred lines. Theor Appl Genet 47:35-39.

Van Ooijen JW (1992) Accuracy of mapping quantitative trait loci in autogamous species. Theor Appl Genet 84:803-811. Associate Editor: José Francisco Ferraz de Toledo 